\title{
Peningkatan Daya Output Photovoltaik Dengan Penambahan Lapisan Kaca Film Pada Permukaannya
}

\author{
Andi Pawawoi* dan Vegi Apria Pranata \\ Jurusan Teknik Elektro, Fakultas Teknik, Universitas Andalas, Padang, Sumatera Barat, Indonesia \\ ${ }^{*}$ Corresponding author, e-mail: andi.pawawoi@eng.unand.ac.id
}

\begin{abstract}
Abstrak - Salah satu parameter yang mempengaruhi output photovoltaik adalah temperatur. Temperatur kerja optimum photovoltaik berada pada kisaran $25^{\circ} \mathrm{C}$. Setiap kenaikan temperatur akan menyebabkan penurunan output photovoltaik. Kaca film adalah salah satu material yang banyak digunakan untuk memblok panas namun tetap mampu melewatkan cahaya matahari. Karakteristik utama kaca film yang dapat memblok panas dikenal dengan istilah IRR (Infra Red Rejected) dan kemampuan melewatkan cahaya dikenal dengan istilah VLT (Visible Light Transmittance). Semakin besar VLT maka semkin kecil kemampuannya memblok panas, demikian juga sebaliknya. Dalam aplikasinya pada photovoltaik, perlu dicari dan diuji kaca film yang sesuai untuk peningkatan daya output photovoltaik. Dalam tulisan ini diuraikan hasil pengujian 3 jenis kaca film dengan VLT yang berbeda, dipilih kaca film dengan VLT tertinggi, sedang dan rendah sesuai yang ada di pasaran, yaitu VLT: 90\%, 72\% dan 60\%. Ketiga kaca film tersebut diaplikasikan dengan cara ditempelkan pada permukaan photovoltaik. Pengujian dilakukan dengan membandingkannya dengan photovoltaik standar (tanpa kaca film) pada cuara cerah dari jam 10.00 hingga jam 14.00 masing-masing selam 3 hari. Hasilnya menunjukkan photovoltaik dilapisi kaca film dengan VLT $90 \%$ mampu meningkatkan daya output rata-rata 49,36\%, sementara yang dilapisi kaca film dengan VLT $72 \%$ dan $60 \%$ mengalami penurunan daya berturut-turut $-6,53 \%$ dan $-26,20 \%$
\end{abstract}

Kata Kunci : Daya Photovoltaik, Kaca film, Reduksi panas

\begin{abstract}
One of the parameters that affect photovoltaic output is temperature. The optimum working temperature of photovoltaic is in the range of $25^{\circ} \mathrm{C}$. Any increase in temperature will cause a decrease in photovoltaic output. Window film is one of the most widely used materials to block heat while still being able to pass sunlight. The main characteristic of window film that can block heat is known as the IRR (Infra Red Rejected) and the ability to pass light is known as the VLT (Visible Light Transmittance). The greater the VLT, the smaller its ability to block heat, and vice versa. In its application to photovoltaics, it is necessary to find and test suitable window film for increasing the photovoltaic output power. In this paper, the results of testing of 3 types of window films with different VLT, the highest, medium and low VLT films chosen according to the market, namely VLT: $90 \%, 72 \%$ and $60 \%$. The third window film is applied by sticking it to the surface of the photovoltaic. The test is carried out by comparing it with standard photovoltaic (without window film) on sunny weather from 10:00 to 14:00 each for 3 days. The results showed that photovoltaic film coated with $90 \%$ VLT was able to increase the average output power by $+49.36 \%$, while those coated with $72 \%$ and $60 \%$ VLT had decreased power respectively $-6.53 \%$ and $26.20 \%$
\end{abstract}

Keywords : Photovoltaic power, Window film, Heat reduction

\section{Pendahuluan}

Temperatur merupakan salah satu variabel yang mempengaruhi efisiensi daya photovoltaik. Umumnya daya maksimum ( $\left.\mathrm{P}_{\mathrm{MAX}}\right)$ sebuah photovoltaik diperoleh pada pengujian standar dengan irradiasi $1000 \mathrm{~W} / \mathrm{m}^{2}$ dan temperatur $25^{\circ} \mathrm{C}$. Koefisien temperatur terhadapat daya output photovoltaik bernilai negatif, yang berarti setiap kenaikan temperatur akan menurunkan daya output.
Dalam realisasinya, intensitas cahaya yang semakin tinggi juga akan menyebabkan temperatur yang semakin tinggi pula [1].

Salah satu cara yang dapat dilakukan untuk mengurangi temperatur yang tinggi adalah dengan menggunakan heatsink. Penggunaan heatsink pada photovoltaik kurang efektif karena kontak antara heatsink dengan photovoltaik sulit dilakukan secara sempurna sehingga pengurangan panasnya tidak 
optimal. Cara lain yang dapat dilakukan adalah dengan menggunakan fluida radiator coolant yang biasanya digunakan pada sepeda motor. Hal ini juga kurang efektif karena diperlukan penambahan wadah fluida pada bagian photovoltaik yang didinginkan dan juga sangat rentan terhadap kebocoran. Oleh karena itu diperlukan suatu sistem lain yang lebih sederhana dan mudah untuk diaplikasikan [1-3].

Kaca film merupakan pelapis kaca yang berfungsi untuk menolak energi panas matahari dan mengurangi intensitas cahaya yang melewatinya. Kaca film biasanya digunakan banyak orang untuk melapisi kaca pada mobil, kaca rumah dan lain sebagainya. Ada beberapa karakteristik yang biasanya dijadikan acuan dalam memilih kaca film yang sesuai dengan kebutuhan, diantaranya Darkness (tingkat kegelapan), Ultra Viloet Rejected (UVR), Visible Light Transmittance (VLT), Infra Red Rejected (IRR), dan Total Solar Energy Rejected (TSER) [4].

Jika kaca film diterapkan pada photovoltaik, maka ada dua karakteristik yang perlu diperhatikan yaitu; IRR dan VLT.

- VLT (Visible Light Transmittance) merupakan jumlah persentase cahaya yang dapat menembus kaca film dimana semakin besar persentase VLT nya maka jumlah cahaya yang masuk akan semakin besar pula.

- IRR (Infra Red Rejected) merupakan kemampuan kaca film untuk menolak panas matahari, dimana semakin besar persentase maka akan semakin baik dalam menolak panas

IRR dan VLT yang tinggi merupakan karakteristik kaca film yang baik diterapkan pada photovoltaik. Namun dalam realitanya, pada sebuah kaca film yang ada di pasaran saat ini, kedua karakteristik tersebut umumnya memiliki nilai saling berlawanan, jika IRR tinggi maka VLT-nya rendah, demikian juga sebaliknya.

Dalam penerapannya pada photovoltaik diperlukan pemilihan kaca film yang tepat dan pengujian untuk mendapatkan karakteristik kaca film yang dapat memaksimalkan daya output photovoltaik.

\section{Karakteristik Photovoltaik dan Kaca Film}

\subsection{Pengaruh Temperatur terhadap Photovoltaik}

Irradiance bukan satu-satunya parameter eksternal yang memiliki pengaruh penting terhadap kurva daya photovoltaik, ada juga pengaruh suhu.
Komponen semikonduktor seperti dioda sensitif terhadap perubahan suhu, begitu pula dengan photovoltaik. Pada gambar 1 terlihat perubahan suhu berpengaruh besar terhadap $\mathrm{V}_{\mathrm{oc}}$, hal ini berlawanan dengan pengaruh irradiance. Kenaikan irradiance berbanding lurus dengan kenaikan suhu [5-8].

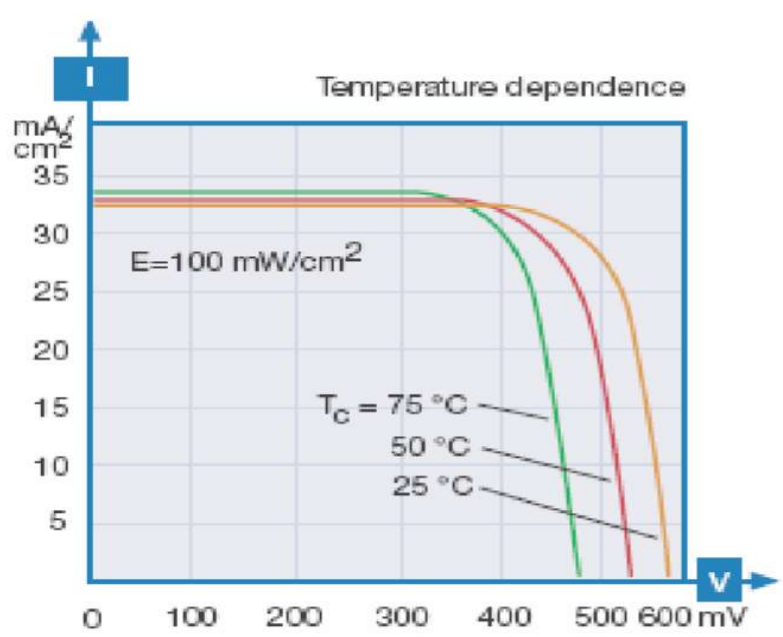

Gambar 1 Karakteristik V-I terhadap perubahan temperatur [5]

Peningkatan temperatur ini dapat berpengaruh pada daya keluaran yang dihasilkan panel photovoltaik. Setiap kenaikan temperatur panel surya $1^{\circ} \mathrm{C}$ (dari $25^{\circ} \mathrm{C}$ ), akan mengakibatkan berkurangnya sekitar $0,5 \%$ dari daya maksimum photovoltaik pada suhu $25^{\circ} \mathrm{C}$ [6].

\subsection{Kaca Film}

Kaca film merupakan kaca dengan bahan penyusun utama berupa silika yang terlapisi film (lapisan tipis) yang berfungsi mengurangi daya tembus cahaya dan daya tembus pandang pada kaca. Kaca film banyak digunakan pada mobil sebagai penolak sinar matahari yang mengandung ultraviolet dan infra merah yang bila radiasinya berlebihan akan membahayakan manusia. Selain itu, kaca film juga berfungsi sebagai piranti keamanan karena bila terjadi keretakan, kaca film yang berbahan polyester, logam dan perekat khusus dapat mempertahankan kaca agar tidak mudah pecah [4].

Penggunaan kaca dengan permukaan gelap akan menyerap lebih banyak cahaya dibandingkan dengan kaca yang memiliki permukaan cerah. Sama halnya bila permukaannya kasar akan menyerap lebih banyak cahaya dibandingkan dengan licin. 
Kaca merupakan material padat yang bening, transparan dan mudah pecah bila terkena benturan yang kuat. Umumnya kaca terbuat dari bahan dasar pasir kuarsa, soda abu, dolomite, dan lain-lain. Pada kaca film, lapisan tipis (film) berbahan polyester ditambahkan pada kaca agar kaca tersebut dapat mengurangi radiasi cahaya yang mengenai kaca tersebut. Pengurangan radiasi cahaya tersebut terjadi karena adanya kemampuan untuk merefleksikan cahaya. Selain itu, kaca film juga dapat merefraksikan (membelokkan) cahaya, sebagaimana terlihat pada gambar 2 .

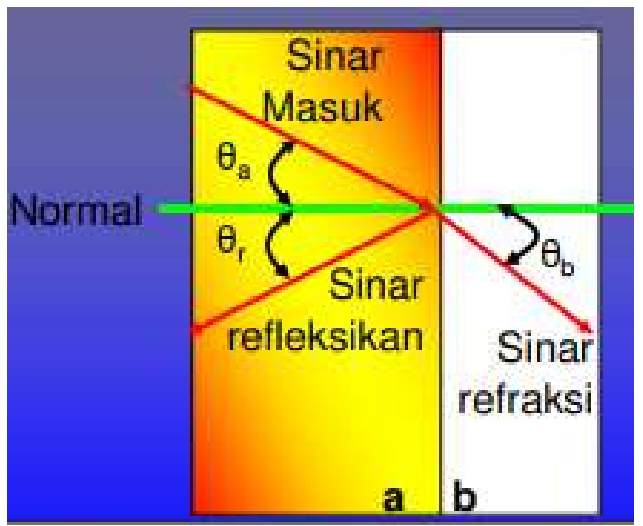

Gambar 2 Refleksi dan refraksi cahaya saat mengenai permukaan photovoltaik

\subsection{Sifat-Sift Kaca Film}

\subsubsection{Visible Light Transmittance (VLT)}

VLT atau penerusan cahaya (tampak) merupakan besaran yang menunjukkan besarnya cahaya yang diteruskan. Semakin kecil nilai VLT maka kaca film semakin terlihat gelap. Di pasaran, konsumen kaca film mengelompokkan kaca film berdasarkan tingkat kegelapannya, yang sebenarnya angkanya berkebalikan dengan data spesifikasi kaca film yang menggunakan VLT. Berikut ini beberapa tingkat VLT

- VLT $60 \%$ - 75\% : Kegelapan kaca film 20\%

- VLT 50\% - 59\% : Kegelapan kaca film 30\%

- VLT 30\% - 49\% : Kegelapan kaca film 40\%

- VLT 11\%-29\% : Kegelapan kaca film 60\%

- VLT 2\%-10\% : Kegelapan kaca film 80\%

Seperti misalnya VKOOL70 mempunyai VLT sebesar $70 \%$ yang berarti $70 \%$ dari cahaya tampak yang dapat menembus kaca film. Di pasaran, kaca film ini dikatakan mempunyai kegelapan $20 \%$. Semakin besar angka VLT ini, berarti semakin bening kaca film tersebut.

\subsubsection{Total Solar Energy Rejection (TSER)}

TSER adalah ukuran yang menggambarkan energi matahari $(\mathrm{UV}+$ visible light + IR) yang diblokir, oleh kaca film

Energi Sinar matahari terdiri dari sinar infra merah 53\%, cahaya tampak 44\% dan sinar UV 3\%. Semua dari 3 gelombang elektromagnetik ini membentuk apa yang dikenal sebagai spektrum matahari dan energi gabungannya diistilahkan total energi matahari.

Presentase TSER merupakan spesifikasi kaca film utama yang harus kita perhatikan dalam memilih kaca film yang baik untuk meredam panas matahari. Angka TSER dipengaruhi oleh VLT, Infrared Rejected, Ultraviolet Rejected, dan unsurunsur lainnya

kaca film dengan TSER lebih tinggi tidak selalu berarti film tersebut berperforma lebih baik. TSER tinggi (Total Solar Energy Rejected) juga berarti film jauh lebih gelap atau sangat reflektif. Jadi cara terbaik untuk menilai antara film adalah membandingkan film dengan VLT (visible light transmittance) yang sama.

\subsubsection{Ultraviolet Rejection (UVR)}

Ultraviolet Rejection/Blocked merupakan penandaan dari kemampuan kaca film menolak sinar ultraviolet, semakin besar nilainya maka semakin bagus. Sinar ini dalam jangka panjang dapat memudarkan warna, merusak material plastik. Umumnya, kaca film yang beredar di pasaran mempunyai UVR di atas $90 \%$.

\subsubsection{Infrared Rejection (IRR)}

Infrared Rejection adalah nilai kemampuan menolak panas, semakin besar persentasenya maka semakin baik dalam menolak panas. Pada dasarnya, sinar Inframerah adalah sinar radiasi yang tidak terlihat, dengan ukuran 700 sampai 2.500 nanometer.

\section{Metoda}

\subsection{Pemilihan Kaca film}

Pemilihan kaca film dilakukan dengan mengacu pada nilai VLT dan IRR dari kaca film yang ada di pasaran. Untuk penerapan sebagai pendingin photovoltaik diperlukan kaca film dengan nilai VLT dan IRR yang tinggi keduanya. Kaca film yang ada di pasaran dengan nilai VLT tinggi memiliki IRR yang rendah, begitu juga sebaliknya, oleh karena itu dalam penelitian ini dipilih 3 jenis 


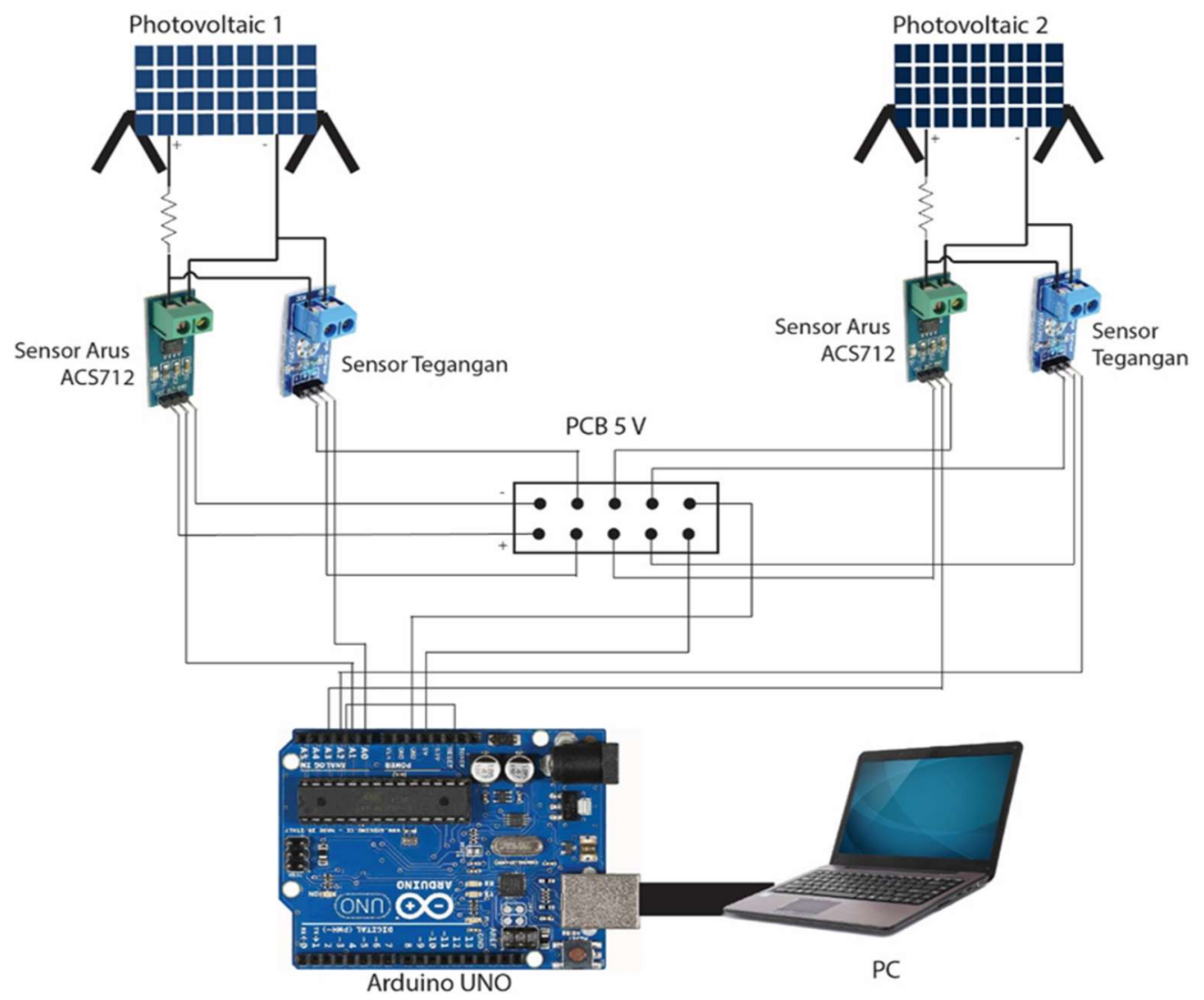

Gambar 3. Skema Rangkaian Pengujian

kaca film dengan tingkat VLT yang berbeda sebagaimana terlihat pada tabel 1 berikut:

Tabel 1. Kaca film yang digunakan

\begin{tabular}{|l|c|c|l|}
\hline No & VLT & IRR & \multicolumn{1}{|c|}{$\begin{array}{c}\text { Tingkat Kegelapan } \\
\text { (Merek) }\end{array}$} \\
\hline 1 & $90 \%$ & 11 & $10 \%$ (Sunprotect) \\
2 & $72 \%$ & 22 & $20 \%$ (Aurora) \\
3 & $60 \%$ & 30 & $40 \%$ (Sunprotect) \\
\hline
\end{tabular}

\subsection{Pengujian}

Pengujian dilakukan dengan membandikan daya keluaran dari photovoltaik yang permukaannya dilapisi kaca film terhadap photovoltaik standar (tanpa dilapisi kaca film) pada beban yang sama. Tahanan beban diset pada nilai yang memberikan daya maksimum $\left(\mathrm{P}_{\mathrm{MPP}}\right)$ pada irradiasi maksimum. Pengukuran arus dan tegangan kedua photovoltaik dilakukan bersamaan secara ril time menggunakan interface arduino seperti terlihat pada skema rangkain pengujian gambar 3. Rekam data dilakukan per 10 menit dari jam 10.00 sampai 14.00 WIB selama 3 hari. Pengukuran temperatur dan irradiasi dilakukan secara manual pada skala waktu yang sama. Pengukuran temperatur dilakukan pada sisi atas dan bawah photovoltaik menggunakan termometer infra merah.

Pengujian untuk semua jenis kaca film yang dipilih dilakukan dengan metode yang sama pada masing-masing 3 hari yang lain.

\subsection{Analisa}

Analisa dilakukan dengan menghitung persentase peningkatan daya output $\left(\mathrm{P}_{\mathrm{p}}\right)$ photovoltaik yang dilapisi dengan kaca film $\left(\mathrm{P}_{\mathrm{dkf}}\right)$ terhadap daya output photovoltaik standar $\left(\mathrm{P}_{\text {std }}\right)$ menggunakan persamaan:

$$
P_{p}=\frac{P_{d k f}-P_{s t d}}{P_{s t d}} \times 100 \%
$$

Perhitungan dilakukan untuk setiap pasang data yang diambil per 10 menit, selanjutnya nilai ratarata persentase dihitung dari data selama 3 hari percobaan. Analisa yang sama dilakukan terhadap data dari ke 3 jenis kaca film yang digunakan 


\section{Hasil dan Analisa}

\subsection{Hasil}

Pengujian photovoltaik yang dilapisi kaca film selalu disandingkan dengan photovoltaik standar. Photovoltaik standar ini tidak dilapisi kaca film diperuntukkan sebagai pembanding. Dilakukan 3 pengujian sesuai jumlah kaca film yang dipilih, yaitu: pengujian I, II, III berturut-turut untuk kaca film VLT $90 \%, 72 \%$, dan $60 \%$. Masing-masing diuji dalam 3 hari pada kondisi cuaca cerah, sehingga dibutuhkan 9 hari untuk semua kaca film. Dari pengujian ini diperoleh data rata-rata daya per 10 menit selama 3 hari dari setiap kaca film sebagaimana disajikan dalam tabel 2 .

\subsection{Analisa dan pembahasan}

Dari data tabel 2 terlihat bahwa pada pengujian I yaitu pengujian photovoltaik yang dilapisi kaca film dengan VLT 90\% memberikan daya output yang lebih tinggi dari photovoltaik standar. Sementara 2 pengujian berikutnya menunjukkan bahwa photovoltaik yang dilapisi kaca film dengan VLT $72 \%$ dan $60 \%$ justru memberikan daya output yang lebih rendah dari kondisi standar.
Dengan menggunakan persamaan (1) diperoleh persentase peningkatan daya output photovoltaik yang dilapisi kaca film terhadap photovoltaik standar untuk masing-masing tingkat VLT kaca film sebagaimana terlihat pada kurva gambar 5 . Persentase positif pada VLT 90\% menunjukkan bahwa terjadi peningkatan daya dan persentase negatif pada VLT $72 \%$ dan $60 \%$ menunjukkan terjadi penurunan daya.

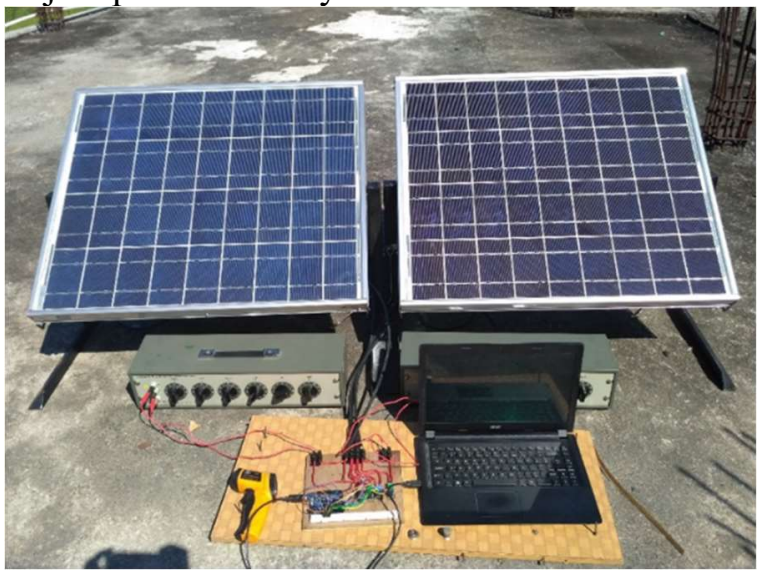

Gambar 4. Pengujian photovoltaik dilapisi kaca film disandingkan dengan photovoltaik standar

Tabel 2. Daya output dan penurunan temperatur rata-rata hasil pengujian

\begin{tabular}{|c|c|c|c|c|c|c|c|c|c|}
\hline \multirow{3}{*}{ Waktu } & \multicolumn{3}{|c|}{ Nilai rata-rata pengujian I } & \multicolumn{3}{|c|}{ Nilai rata-rata pengujian II } & \multicolumn{3}{|c|}{ Daya rata-rata pengujian III } \\
\hline & \multicolumn{2}{|c|}{ Daya output PV } & \multirow{2}{*}{$\begin{array}{c}\text { Penurunan } \\
\text { Temp. } \\
(\%)\end{array}$} & \multicolumn{2}{|c|}{ Daya output PV } & \multirow{2}{*}{$\begin{array}{c}\text { Penurunan } \\
\text { Temp. } \\
(\%)\end{array}$} & \multicolumn{2}{|c|}{ Daya output PV } & \multirow{2}{*}{$\begin{array}{c}\text { Penurunan } \\
\text { Temp. } \\
(\%)\end{array}$} \\
\hline & $\begin{array}{c}\text { PV } \\
\text { standar }\end{array}$ & $\begin{array}{c}\text { PV+VLT } \\
90 \%\end{array}$ & & $\begin{array}{c}\text { PV } \\
\text { standar }\end{array}$ & $\begin{array}{c}\text { PV+VLT } \\
72 \%\end{array}$ & & $\begin{array}{c}\text { PV } \\
\text { standar }\end{array}$ & $\begin{array}{c}\text { PV+VLT } \\
60 \%\end{array}$ & \\
\hline 10.00 & 17,60 & 25,11 & 7,19 & 17,48 & 15,89 & 8,33 & 16,95 & 11,55 & 11,03 \\
\hline 10.10 & 17,78 & 24,83 & 7,29 & 17,52 & 16,04 & 8,49 & 17,25 & 11,67 & 12,02 \\
\hline 10.20 & 17,87 & 24,83 & 9,63 & 17,77 & 16,62 & 10,72 & 17,19 & 11,84 & 13,97 \\
\hline 10.30 & 18,10 & 25,14 & 8,64 & 16,64 & 16,03 & 10,52 & 17,58 & 11,96 & 13,56 \\
\hline 10.40 & 17,97 & 25,23 & 10,21 & 17,21 & 16,63 & 10,76 & 17,87 & 12,19 & 16,16 \\
\hline 10.50 & 18,33 & 25,55 & 10,25 & 18,06 & 16,96 & 10,31 & 18,32 & 13,24 & 16,13 \\
\hline 11.00 & 18,09 & 25,69 & 10,51 & 18,33 & 16,98 & 9,52 & 18,43 & 13,36 & 17,09 \\
\hline 11.10 & 18,16 & 25,67 & 10,99 & 17,87 & 17,09 & 8,14 & 18,69 & 13,91 & 15,18 \\
\hline 11.20 & 17,79 & 26,32 & 9,53 & 18,41 & 17,20 & 7,36 & 17,76 & 14,04 & 13,80 \\
\hline 11.30 & 18,08 & 28,58 & 9,42 & 18,46 & 17,53 & 6,24 & 17,62 & 14,04 & 11,36 \\
\hline 11.40 & 18,69 & 29,57 & 6,90 & 18,40 & 17,64 & 4,95 & 19,05 & 14,29 & 10,44 \\
\hline 11.50 & 19,53 & 30,31 & 4,75 & 18,97 & 17,17 & 4,61 & 18,96 & 14,08 & 8,74 \\
\hline 12.00 & 20,70 & 30,26 & 6,25 & 19,34 & 17,55 & 6,26 & 18,97 & 14,49 & 10,20 \\
\hline 12.10 & 20,68 & 30,36 & 6,12 & 19,90 & 17,63 & 7,44 & 19,53 & 14,77 & 10,19 \\
\hline 12.20 & 20,17 & 29,89 & 6,47 & 19,96 & 17,53 & 9,05 & 19,31 & 14,49 & 11,66 \\
\hline 12.30 & 19,27 & 30,12 & 3,97 & 20,54 & 17,94 & 7,56 & 19,02 & 14,71 & 11,14 \\
\hline 12.40 & 19,62 & 29,80 & 2,02 & 21,46 & 17,90 & 7,74 & 18,77 & 14,42 & 10,19 \\
\hline 12.50 & 18,62 & 30,05 & 1,42 & 20,51 & 17,87 & 7,81 & 17,88 & 14,20 & 10,66 \\
\hline 13.00 & 18,93 & 29,67 & 1,50 & 19,32 & 17,73 & 8,13 & 18,50 & 14,25 & 10,01 \\
\hline 13.10 & 18,72 & 30,12 & 1,23 & 18,93 & 18,07 & 7,44 & 17,84 & 14,00 & 11,00 \\
\hline 13.20 & 18,46 & 28,80 & 0,91 & 18,42 & 17,67 & 5,78 & 17,48 & 14,02 & 10,56 \\
\hline 13.30 & 18,66 & 27,26 & 3,02 & 18,64 & 17,53 & 7,42 & 17,30 & 13,92 & 11,83 \\
\hline 13.40 & 18,45 & 26,40 & 4,70 & 18,33 & 17,35 & 8,93 & 17,53 & 13,74 & 12,76 \\
\hline 13.50 & 18,68 & 25,46 & 4,11 & 17,81 & 17,33 & 7,24 & 17,28 & 13,82 & 10,60 \\
\hline 14.00 & 18,43 & 25,28 & 4,91 & 18,14 & 17,30 & 6,58 & 17,55 & 13,99 & 10,44 \\
\hline Rata-rata & 18,70 & 27,61 & 6,08 & 18,66 & 17,25 & 7,89 & 18,11 & 13,64 & 12,03 \\
\hline
\end{tabular}


Peningkatan daya pada photovoltaik yang dilapisi kaca film VLT 90\% dari jam 10.00 hingga jam 14.00 mencapai rata-rata $49,36 \%$, dengan nilai tertinggi $62,92 \%$ dan terendah $40,13 \%$. sementara yang dilapisi kaca film dengan VLT $72 \%$ dan $60 \%$ berturut-turut adalah $-6,53 \%$ dan $-26,20 \%$

Rata-rata temperatur permukaan semua photovoltaik yang dilapisi kaca film lebih rendah dari temperatur permukaan photovoltaik standar, dengan kata lain penambahan kaca film menurunkan temperatur permukaan photovoltaik. Penurunan terbesar terjadi pada photovotaik yang dilapisi kaca film VLT 60\% yaitu sebesar 12,03\%. yang dilapisi kaca film dengan VLT 72\% dan 90\% berturut-turut adalah $7,89 \%$ dan $6,08 \%$. Grafik persentase penurunan temperatur pada 3 pengujian diperlihatkan pada gambar 6 .

Penambahan lapisan kaca film VLT 90\% pada PV mampu meningkatkan daya output PV, hal ini disebabkan adanya penurunan temperatur kerja sekitar $6 \%$ walaupun juga terjadi penurunan intensitas cahaya yang diterima PV sekitar $10 \%$. Pada PV yang dilapisi kaca film $72 \%$ dan dan $60 \%$ walaupun terjadi penurunan temperatur sekitar $7,89 \%$ dan $12,03 \%$ namun karena terjadi penurunan intensitas cahaya yang cukup signifikan yaitu $28 \%$ dan $40 \%$ maka terjadi penurunan daya output PV

\section{Kesimpulan}

Kaca film dengan VLT (Visible Light Transmittance) 90\% mampu meningkatkan daya output photovoltaik rata-rata 49,36\% dari kondisi standar tanpa kaca film. Kaca film dengan VLT (Visible Light Transmittance) $72 \%$ dan 60\% tidak mampu meningkatkan daya output photovoltaik walaupun kaca film ini bisa memberikan penurunan temperatur yang lebih besar. Kaca film ini justru menyebabkan terjadinya penurunan daya output.

\section{Ucapan Terima Kasih (Acknowledgement)}

Penulis bersyukur dan berterima kasih atas bantuan yang diberikan oleh Jurusan Teknik Elektro Fakultas Teknik Universitas Andalas untuk mendanai sebagian publikasi ini melalui DIPA FT Unand 2019, (Kontrak No.088/UN.16.09.D/PL/ 2019)

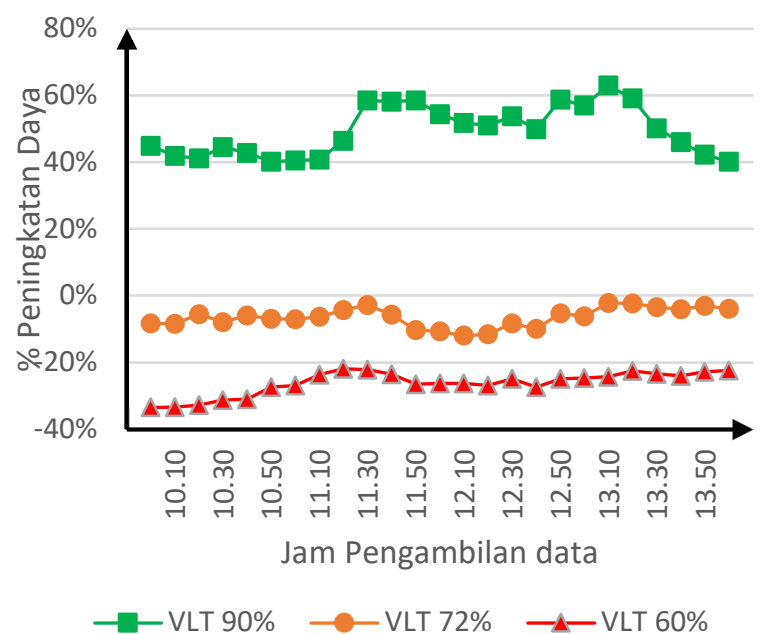

Gambar 5. Grafik persentase peningkatan daya photovoltaik yang dilapisi kaca film terhadap photovoltaik standar

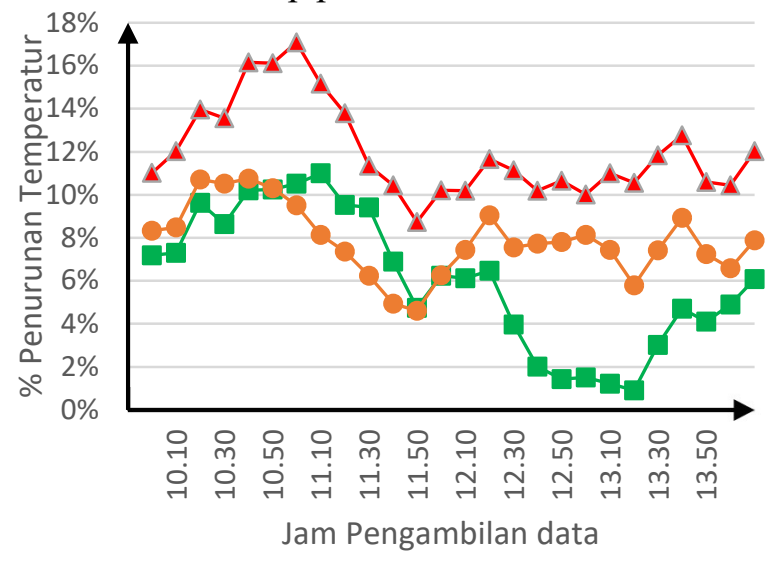

$\longrightarrow$ VLT 90\% —VLT 72\% —A VLT 60\%

Gambar 6. Grafik persentase penurunan temperatur permukaan photovoltaik yang dilapisi kaca film terhadap photovoltaik standar

\section{Daftar Pustaka}

[1] Andi Pawawoi, Zulfahmi, Penambahan Sistem Pendingin Heatsink Untuk Optimasi Penggunaan Reflektor Pada Panel Surya Jurnal Nasional Teknik Elektro, Vol: 4, No. 1, Maret 2019

[2] K.A. Moharram, Enhancing the performance of photovoltaic panels by water cooling, Ain Shams Engineering Journal 4, 869-877, 2013

[3] J. Siecker, A review of solar photovoltaic systems cooling technologies, Renewable and Sustainable Energy Reviews, Vol 79, 192-203, Elsevier, 2017. 
[4] Wincos Automotive Film, Spesifikasi Kaca Film, https://www.wincos-ina.co.id, Juni 2019

[5] Cătălin G.P, Efficiency improvement of photovoltaic panels by using air cooled heat sinks, Energy Procedia 85, 425 - 432, Elsevier, 2016

[6] M. dan E. Yohana, Pengaruh Suhu Permukaan Photovoltaik Module 50 watt peak Terhadap Daya Keluaran Yang Dihasilkan Menggunakan Reflektor Dengan Variasi Sudut Reflektor 0, 50, 60, 70, 80, Jurnal Rolasi, vol. 2, no. 4, pp. 14-18, 2010.

[7] Budi Yuwono, Optimalisasi Panel Sel Surya Dengan Menggunakan Sistem Pelacak Berbasis Mikrokontroler T89C51 , FMIPA UNS, Surakarta, 2005.

[8] Foster,Robert, dkk., Solar Energy Renewable Energy and The Environment. Boca Rotan, CRC Press LLC, 2010. 